\title{
Determination of 'Palmer' mango maturity indices using portable near infrared (VIS-NIR) spectrometer
}

\author{
João Paixão dos Santos Neto ${ }^{\mathrm{a}}$, Mateus Wagner Dantas de Assis ${ }^{\mathrm{b}}$, Izabella Parkutz Casagrande ${ }^{\mathrm{a}}$, \\ Luis Carlos Cunha Júnior ${ }^{c}$, Gustavo Henrique de Almeida Teixeira, ${ }^{a}$, \\ ${ }^{\text {a }}$ Universidade Estadual Paulista (UNESP), Faculdade de Ciências Agrárias e Veterinárias (FCAV), Campus de Jaboticabal, Via de acesso Prof. Paulo Donato Castellane s/ \\ n, Jaboticabal, SP CEP 14870-900, Brazil \\ b Centro Universitário UNIFAFIBE, Rua Prof. Orlando França de Carvalho, 325, Bebedouro, SP CEP 14701-070, Brazil \\ c Universidade Federal de Goiás (UFG), Escola de Agronomia (EA), Setor de Horticultura, Rodovia Goiânia Nova Veneza, km 0, Campus Samambaia, Caixa Postal 131, \\ Goiânia, GO CEP 74690-900, Brazil
}

\section{A R T I C L E I N F O}

\section{Keywords:}

Mangifera indica L.

Chemometrics

PLSR

SSC

DM

SWNIRS

\begin{abstract}
A B S T R A C T
'Palmer' mango cultivar is a late season variety which is greatly accepted by European consumers. However, it is common to get reports of fruit quality problems, mainly due to maturity. Thus, the objective of this study was to develop calibration models for soluble solids content (SSC) and dry matter (DM) of 'Palmer' mangoes using portable (VIS-NIR) spectrometer. Interactance spectra were obtained with a portable F-750 spectrometer in the wavelength range of $306-1140 \mathrm{~nm}, 8 \mathrm{~nm}$ spectrum resolution, and 4 scans averaged per spectra. Spectra were used to develop SSC and DM models using partial least square regression (PLSR) with full cross validation. The best SSC calibration model was developed using spectra pre-processed with standard normal variate (SNV), first derivative of Savitzky-Golay and window of $699-999 \mathrm{~nm}$. It was observed a $\mathrm{RMSE}_{\mathrm{CV}}$ of $1.39 \%$, with a $R_{\mathrm{CV}}^{2}$ of 0.87, and RPD of 2.77. Better results were observed for the DM calibration model which was built with raw spectra using the window of $699-981 \mathrm{~nm}$ (RMSE $_{\mathrm{CV}}$ of $8.81 \mathrm{~g} \mathrm{~kg}^{-1}, R_{\mathrm{CV}}^{2}$ of 0.84 , and RPD of 2.51). Poor calibration models were obtained for firmness. The results indicated that portable VIS-NIR spectrometer can be used as a non-destructive technique to assess SSC and DM content for 'Palmer' mangoes. It is necessary to incorporate more sources of variation, to reduce RMSE values and improve robustness, especially for fruit SSC and DM prediction.
\end{abstract}

\section{Introduction}

Mango maturity is determinant for consumer's acceptance as less mature fruit have low soluble solids content (SSC) which affect fruit quality specially flavor (Jha et al., 2007). In the United States of America (USA) market it was observed that 'Tommy Atkins' mangoes with more SSC ( $>13.5 \%$ ) reached $80 \%$ acceptance. On the other hand, mangoes with SSC ranging from 9.5 to $12.6 \%$ the acceptance were inferior then 80\% (Makani, 2009). Therefore, an accurate method for mango maturity determination is imperative for fruit quality.

Mango is a climacteric fruit and it is usually harvested at the hard green stage at the end of its development when fruit are physiologically mature (Bleinroth, 1994). According to Kader et al. (2002), mangoes which will be consumed by nearby markets might exhibit color changes from dark green to light green or even to light yellow. On the other hand, mangoes which will be consumed by distant markets requiring several days of transport are harvest still dark green. Mature hard green mangoes reach superior eating quality when ripe while immature fruit does not (Medlicott et al., 1988).

Various maturity indexes have been suggested for harvesting mangoes. However due to the differences among mango types (monoembryonic and polyembryonic), varieties, production, conditions, and locations, there is no consensus on maturity indices (Mitra and Baldwin, 1997; Yahia, 2011). Paull and Duarte (2011) reported that mango maturity is determined by using criteria such as change in color, fullness of cheeks and hardened endocarp with the indication that the most reliable indicator is when the endocarp has hardened and there is a yellowing of the flesh near the seed, however, this is a destructive test. Other physical parameters include shape, size, lenticels, shoulder growth, pit around pedicel, and specific gravity (Popenoe and Long, 1957; Krishnamurthy and Subramanyam, 1970; Ketsa et al., 1991). Chemical parameters include SSC, acidity, and carbohydrate (starch) content have also been used (Soule and Harding, 1956; Popenoe and Long, 1957; Popenoe et al., 1958; Thanaraj et al., 2009; Yahia, 2011).

\footnotetext{
* Corresponding author.

E-mail address: gustavo@fcav.unesp.br (G.H. de Almeida Teixeira).
} 
Due to the subjective aspects of physical maturity indices (shape, size, lenticels, shoulder growth, pit around pedicel), the inconsistency of specific gravity for some mango varieties (Tandon and Kalra, 1983), and the destructive nature of chemical parameters (Subedi et al., 2007; Paull and Duarte, 2011), non-destructive methods have been suggested as a means to determine maturity in mango fruit and near infrared (NIR) spectroscopy is one of those (Abbott, 1999).

Bench top and/or on-line NIR spectrometers have been used to determine SSC, dry matter content (DM), titratable acidity (TA), pulp firmness, starch content, and other physical-chemical parameters in mango fruit (Jha et al., 2012, 2014; Betemps et al., 2011; Subedi and Walsh, 2011; Valente et al., 2009; Delwiche et al., 2008; Subedi et al., 2007; Mahayothee et al., 2004; Saranwong et al., 2001, 2004; Schmilovitch et al., 2000; Guthrie and Walsh, 1997). However, the evaluation of mango maturity in the packing house might result in postharvest losses as the fruit which do not fulfill the quality standards are discarded.

To solve this problem portable NIR spectrometers have been used to evaluate mango maturity in field as just the fruit in the required maturity stage will be harvested. Maturity index $\left(I_{\mathrm{m}}\right)$ calculated as SSC times dry matter (DM) divided by titratable acidity (TA) was assessed in seven mango varieties (Chausa, Langra, Kesar, Neelam, Dasheri, Mallika, and Maldah) using a portable Luminar 5030 NIR by Jha et al. (2014). Rungpichayapichet et al. (2016) studying the maturity and postharvest quality of 'Nam Dokmai' and 'Si Thong' mangoes reported a standard error of prediction (SEP) for SSC of $1.2 \%$ and a correlation coefficient $\left(R^{2}\right)$ of 0.90 ; a $R^{2}=0.82$, SEP $=4.22 \mathrm{~N}$ for firmness; $R^{2}=0.74$, SEP $=0.38 \%$ for TA; and $R^{2}=0.80$, SEP $=0.80$ for ripening index. Marques et al. (2016) using a portable MicroNIR 1700 reported a root mean square error of prediction (RMSEP) of $0.92{ }^{\circ}$ Brix, $0.51 \%, 0.17 \%$, and $12.2 \mathrm{~N}$ for SSC, DM, TA, and firmness, respectively. More recently, Walsh and Subedi (2016) developed models for in field DM content estimation with $R^{2}$ of 0.94 and root mean square error of cross validation (RMSECV) of $0.68 \%$.

Although results can be found regarding portable NIR spectroscopy to estimate maturity in mango fruit, there is no standard maturity indices for mangoes, mainly due to the diversity of cultivars and growing conditions, therefore it is essential to develop them for a particular cultivar, growing region and for local or export markets (Yahia, 2011). As there is no information related to 'Palmer' mango which is an American (monoembryonic) late season variety largely exported from Brazil to distant markets in Europe and elsewhere, the objective of this study was to develop calibration models for SSC and DM of 'Palmer' mango during fruit development using portable VIS-NIR spectrometer.

\section{Material and methods}

\subsection{Fruit material}

The experiment was set on a commercial orchard located at Cândido Rodrigues $\left(21^{\circ} 19^{\prime} 21^{\prime \prime}\right.$ latitude South, 48 $38^{\prime} 2^{\prime \prime}$ longitude West, $671 \mathrm{~m}$ altitude), São Paulo State, Brazil. A total of 300 panicles were marketed with colored wool when 'Palmer' mango (Mangifera indica L.) trees were in full bloom. A total of 149 fruits were harvested during their development, as such: (i) 91 days after bloom (DAB) $(n=25)$, (ii) $98 \mathrm{DAB}(n=30)$, (iii) $105 \mathrm{DAB}(n=30)$, (iv) $112 \mathrm{DAB}(n=28)$, (v) $119 \mathrm{DAB}(n=25)$, and (vi) $126 \mathrm{DAB}(n=11)$. The stated harvests occurred when the degree-day (DD) accumulated 1434.0, 1539.9, $1634.1,1741.2,1854.6$, and $1970.1^{\circ} \mathrm{C}$, respectively. It is worth note that Souza (2007) reported that 'Palmer' mangoes need 119 days after bloom to maturity (1.962.7 DD).

The calibration models were developed using the dataset from the six harvests (136 fruit) from 2016 season (Table 1).
Table 1

Descriptive statistics of the calibration set for dry matter (DM) and soluble solids content (SSC) of 'Palmer' mangoes.

\begin{tabular}{lllllllllll}
\hline \multirow{2}{*}{ Group } & \multicolumn{3}{l}{ Soluble solids (\%) } & & \multicolumn{4}{l}{ Dry matter $\left(\mathrm{g} \mathrm{kg}^{-1}\right)$} \\
\cline { 2 - 4 } \cline { 7 - 9 } & $N$ & Mean & Range & SD & & $N$ & Mean & Range & SD \\
\hline Calibration & 150 & 7.38 & $21.0-3.8$ & 3.85 & & 150 & 154.8 & $221.2-113.4$ & 22.1 \\
\hline
\end{tabular}

$N$, number; SD, standard deviation.

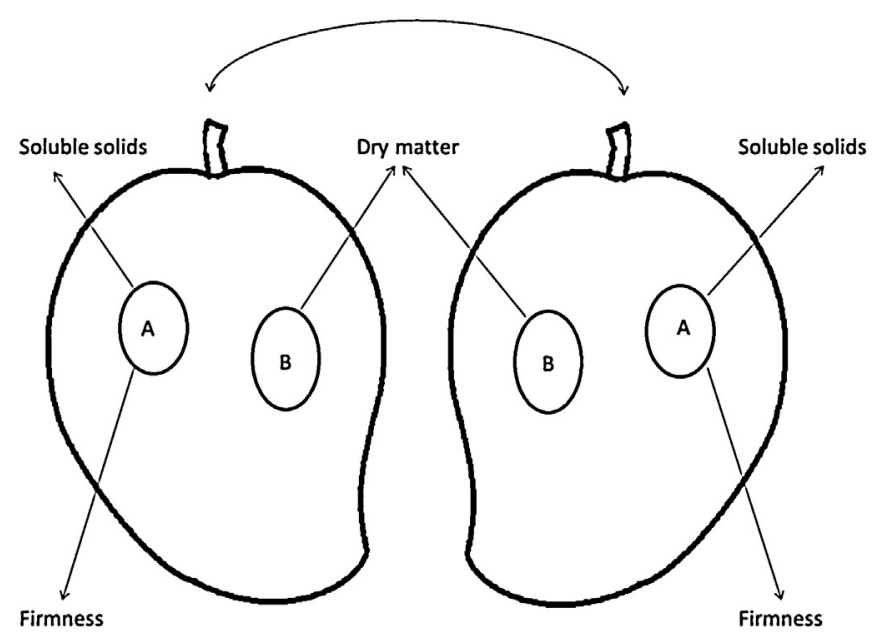

Fig. 1. Places where the near infrared (NIR) spectra were acquired and from where the reference analysis were carried out. (A) Soluble solids content (SSC) and firmness, and (B) dry matter content (DM).

\subsection{Spectra acquisition}

From the 149 fruits two spectra $(n=2)$ were collected from both sides of each fruit ( $n=298$ spectra), on the equatorial region, equidistant from proximal and distal ends according to the methodology described by Subedi et al. (2007), Fig. 1. A portable F-750 (Felix Instruments, Washington, USA) equipped with a Carl Zeiss MMS-1 near infrared spectrometer was used to collected the spectra on the wavelength range of $310-1100 \mathrm{~nm}$, using interactance as optic configuration and a resolution of $8-13 \mathrm{~nm}$. The light source was a halogen lamp.

\subsection{Reference analyses}

\subsubsection{Soluble solids content (SSC)}

The portion A (Fig. 1) where the VIS-NIR spectra were collected for SSC estimation was used to analyze the soluble solids content (SSC) according to the reference method 920.151 reported by A.O.A.C. (1997). It was used a refractometer (Alpha, Atago Co., Ltd., Japan), and the measurements were carried out in duplicate with the results expressed in percentage (\%).

\subsubsection{Dry matter (DM)}

The dry matter content (DM) was determined by sampling a portion of $27 \mathrm{~mm}$ in diameter and with $10 \mathrm{~mm}$ of depth from the portion $\mathrm{B}$ (Fig. 1), after removing the mango epidermis (1-2 mm thick) using a potato peeler. These portions were the same where the VIS-NIR spectra were previously collected for DM estimation. The DM content was measured by the weight loss after $48 \mathrm{~h}$ of air forced dry in an oven set at $105{ }^{\circ} \mathrm{C}$ (Subedi et al., 2007).

\subsection{Chemometrics}

The Unscrambler version 10.3 (Camo, Oslo, Norway) was used for 
data analysis. Spectra were pre-processed using standard normal variate (SNV), multiplicative scatter correction (MSC), de-trend, second polynomial order of the first $\left(\mathrm{d}^{1} \mathrm{~A}\right)$ and second derivative $\left(\mathrm{d}^{2} \mathrm{~A}\right)$ of Savitzky-Golay with smoothing window of ten points $(5+5)$ and five points $(2+2)$, respectively.

Calibration models were developed using the data set from 2016 harvest season (136 fruits - 272 spectra). The samples of all six harvests constituted the calibration set for SSC and DM (Table 1). An attempt was made to correlate VIS-NIR spectra with fruit firmness, but the results were poor which is consistent with previous study (Subedi and Walsh, 2009). Full cross validation was performed using 263 spectra and the calibration models were developed using a partial least squares regression (PLSR) and the performance was described by the statistical terms of coefficient of determination of cross validation $\left(R_{\mathrm{CV}}^{2}\right)$, the root mean square error of cross validation $\left(\mathrm{RMSE}_{\mathrm{CV}}\right.$ ), and RPD (Golic and Walsh, 2006; Nicolai et al., 2007).

\section{Results and discussion}

\subsection{Reference analysis: $S S C$ and $D M$}

The descriptive statistics can be observed in Table 1 . The calibration set has an average SSC of $7.38 \%$ (Table 1). It was observed a rise in SSC from the 91 to $126 \mathrm{DAB}$ with the highest content being observed at $126 \mathrm{DAB}$ (17.9\%), Fig. 2. However, after $112 \mathrm{DAB}$ the SSC started to increase indicating the onset of fruit ripening as SSC biosynthesis is related to storage carbohydrates metabolism (Chitarra and Chitarra, 2005). Therefore, SSC increased during maturation due to the accumulated starch hydrolyzes with formation of sugars (Mitra and Baldwin, 1997). It started to happen after $112 \mathrm{DAB}$, even though fruit had SSC lower than $10 \%$ which indicates mangoes at physiological maturity stage (Ribeiro, 2006; Assis, 2004).

For DM the calibration set has an average DM content of $154.8 \mathrm{~g} \mathrm{~kg}^{-1}$ (Table 1). It was observed a steadily increase in DM from 91 to $126 \mathrm{DAB}$ (Fig. 2). Significant differences $(p<0.05)$ were observed from the $105 \mathrm{DAB}$ and the highest DM content was reported on 119 and $126 \mathrm{DAB}$ (172 and $180 \mathrm{~g} \mathrm{~kg}^{-1} \mathrm{DM}$ ), Fig. 2. The initial changes in DM content compared to $91 \mathrm{DAB}$ happened earlier than SSC, $105 \mathrm{DAB}$ and $112 \mathrm{DAB}$, respectively (Fig. 2). This modification can indicate DM as a good maturity stage index which is in agreement with
Subedi et al. (2007) that reported DM models being more robust in ripening mangoes, with conversion of starch to sugars, than SSC models.

In Australian mango industry the DM has been determined in field using portable NIR spectrometers (Walsh et al., 2004; Subedi et al., 2007) and a DM of $150 \mathrm{~g} \mathrm{~kg}^{-1}$ has been recommended as maturity index to harvest the fruit (AMIA, 2016; Walsh, 2016). By using this quality standard 'Palmer' mangoes should be harvested at $105 \mathrm{DAB}$. It is worth note that the grower from where the mangoes were harvested picketed the fruit at $91 \mathrm{DAB}$, which is 15 days less than the Australian recommendation (Story and Martin, 1996; Bally, 2011), and 28 days less than what Souza (2007) reported that 'Palmer' mangoes need to be harvested (119 DAB). Therefore, the less mature fruit (91 DAB) will not reach superior eating quality (Medlicott et al., 1988).

\subsection{Spectra}

The average raw spectra of each maturity stage obtained with a portable F-750 spectrometer can be seen in Fig. 3. The first absorption bands correspond to the visible wavelength region $(310-750 \mathrm{~nm})$ which presented high absorptions on the violet $(380-440 \mathrm{~nm})$, green (500-565) and red $(625-740 \mathrm{~nm})$ spectral regions (Halliday et al., 2009). This trend reflects the 'Palmer' mango peel color which is characterized by a strong red color, but might also vary from yellow to green depending on maturity and exposure to light (Manica, 2001).

The visible wavelength region $(310-750 \mathrm{~nm}$ ) of the spectra was dominated by a large number of fruit showing high absorptions on the violet $(380-440 \mathrm{~nm})$ and green $(500-565 \mathrm{~nm})$ spectral regions. As the majority of the fruit were harvested in early maturity stages (91-112 DAB) in relation to more mature fruit (119 and $126 \mathrm{DAB}$ ), the chlorophyll content in immature 'Palmer' mangoes peel might have affected the visible part of the spectra (Fig. 3). During mango maturation and ripening chloroplasts in the peel are transformed into chromoplasts containing red and yellow pigments (Lizada, 1993), and cultivars such as 'Palmer' also develop a reddish blush due to anthocyanins (Manica, 2001). The presence of reddish pigments is confirmed by the absorption on the red $(625-740 \mathrm{~nm})$ spectral region and correspond the more mature 'Palmer' mangoes.

The NIR spectra were obtained on the wavelength range of

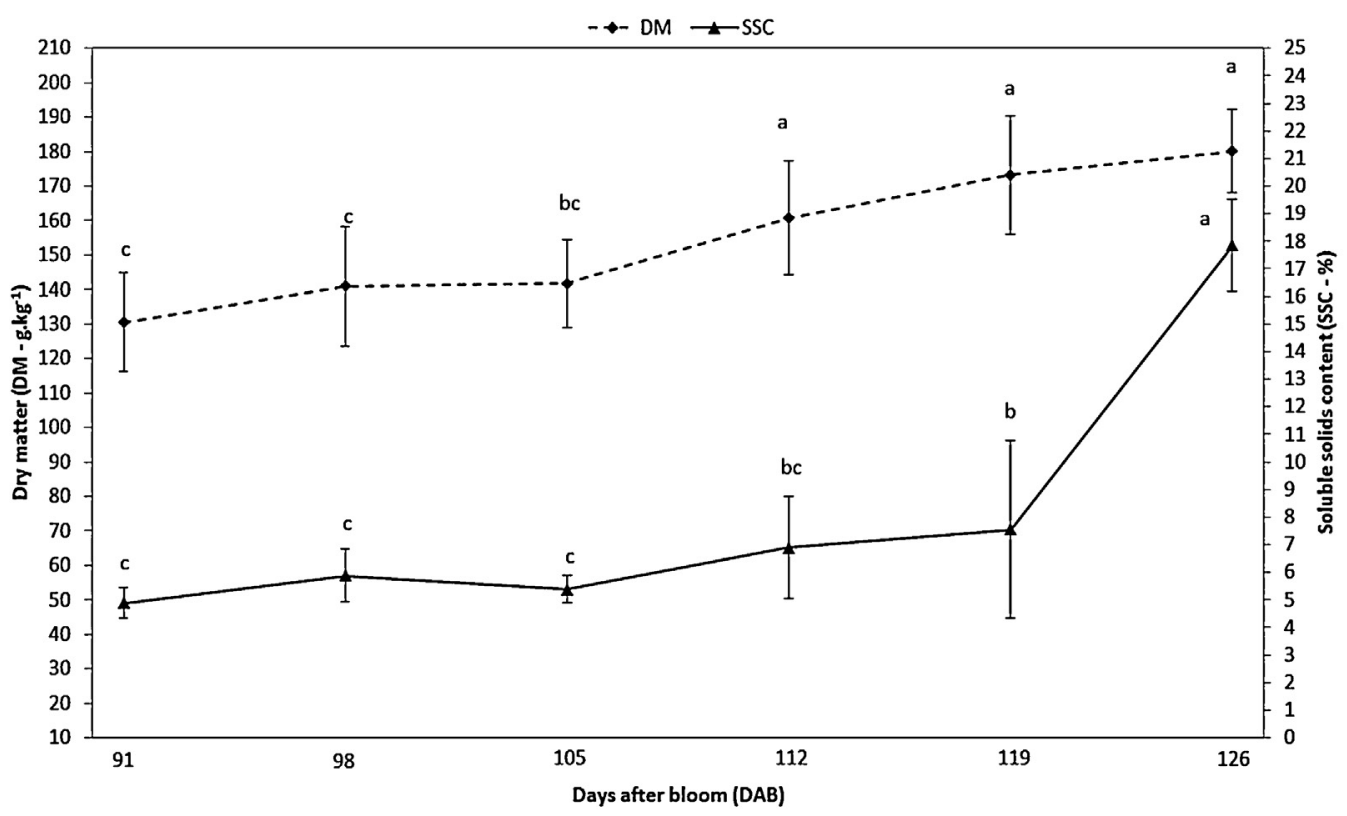

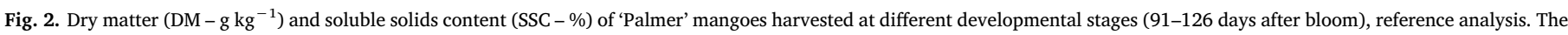

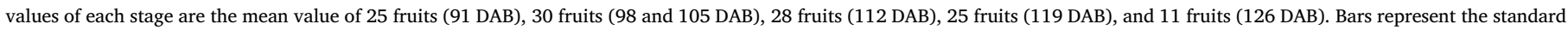
deviation (SD). 


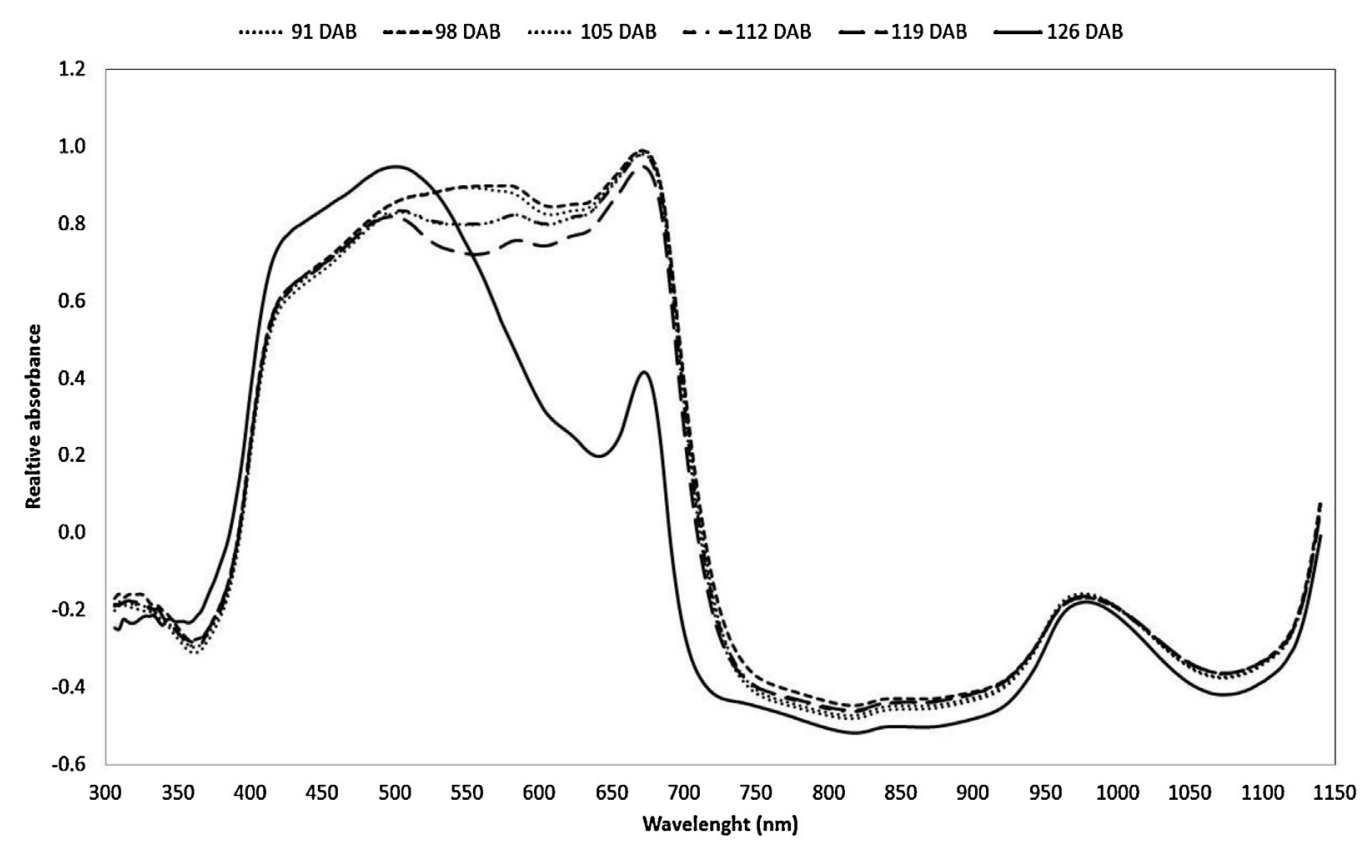

Fig. 3. Mean raw spectra of 'Palmer' mango harvested at different developmental stages (91-126 days after bloom - DAB).

750-1131 nm (Fig. 3), which is named short wavelength near infrared spectroscopy (SWNIR), Subedi et al. (2007). In this spectral region it was observed intense absorption bands on the range of 900-1070 nm, which correspond to the water molecular vibrations as the absorptions bands from 1000 and $1400 \mathrm{~nm}$ are referred as the first and second water overtones (Xiaobo et al., 2010). The NIR spectra reflect the presence of water in abundance as the case of fresh 'Palmer' fruit that have $79.7 \%$ moisture (TACO, 2011). Other aspect that has to be state is the similarities among NIR spectra even with fruit from different maturity (Fig. 3).

In the short wavelength near infrared region $(750-1131 \mathrm{~nm})$ was observed a peak (920-1041) on the second $\mathrm{OH}$ overtone $(960 \mathrm{~nm})$ region (Xiaobo et al., 2010), which correspond to the water molecular vibrations basically caused by the mango moisture content. However, carbohydrate (starch and sugar) also are also related to water and sugar $\mathrm{OH}$ and $\mathrm{CH}$ stretching (third overtone stretch at $910 \mathrm{~nm}$ ) bands (Golic et al., 2003). Fresh 'Palmer' mangoes have $79.7 \%$ moisture (TACO, 2011) and the presence of water dominate the NIR spectra (Fig. 2) as previously observed in other mango varieties (Saranwong et al., 2004; Subedi and Walsh, 2009; Jha et al., 2014; Rungpichayapichet et al., 2016).

To perform the PLSR the spectra needed to be processed as noise was presented on the range of $312-360 \mathrm{~nm}$, which was eliminated, and light scattering at the fruit surface was observed (Fig. 3). In other to reduce the influence of light scattering and the base line drift various pre-processing were applied to the spectra (data not shown), and SNV and first derivative of Savitzky-Golay with five smoothing point $\left(\mathrm{d}^{1} \mathrm{~A}\right)$ were considered the best results.

\subsection{PLS prediction models}

\subsubsection{SSC}

Among all pre-treatments, the SNV and first derivative of Savitzky-Golay using the spectra window of 699-999 nm resulted in better SSC predictions with the calibration model being developed with 7 latent variables $(\mathrm{LV}), \mathrm{RMSE}_{\mathrm{CV}}$ of $1.39 \%$ and a $R_{\mathrm{CV}}^{2}$ of 0.87 , with a RPD of 2.77. The predicted SSC by full cross validation can be observed in Fig. 4.

The RMSE $E_{C V}$ value of $1.39 \%$ for SSC is in agreement to Nicolai et al. (2007), who reported values of $1.0-1.5^{\circ}$ Brix as being consistent with studies that used external validation groups, with fruit coming from different orchards and periods of the year. According to Nicolai et al. (2007), the RPD value of 2.77 allows good to excellent prediction as it is higher than 2.5 .

Comparing the performance of the SSC prediction model with other studies, the RMSE $E_{\mathrm{CV}}$ value of $1.39 \%$ was quite similar to the SEP of $1.2 \%$ reported by Rungpichayapichet et al. (2016) who studied 'Nam Dokmai' and 'Si Thong' mango varieties using a VIS/NIR spectrometer (HandySpec Campo 1000, tec5AG, Oberursel, Germany) on the range of 700-1100 nm (SWNIR). On the other hand, lower SEP values were reported by Saranwong et al. (2003) using a 'FT20' spectrometer (Fantec, Japan) on ripe 'Carabao' mangoes $\left(0.40 \% ; R_{\mathrm{V}}^{2}=0.96\right.$; $850-1000 \mathrm{~nm}$, and $0.55 \% ; R_{\mathrm{V}}^{2}=0.88 ; 900-1000 \mathrm{~nm}$ ) and by Marques et al. (2016) using a MicroNIR 1700 (VIAVI, Santa Rosa, CA, USA) on the wavelength range of $950-1650 \mathrm{~nm}$ (RMSE $_{\mathrm{p}}$ of $0.92^{\circ} \mathrm{Brix}$ ) for 'Tommy Atkins' mango.

More robust models were developed by Subedi et al. (2007) studying 'Kensington Pride', 'R2E2', 'Celebration', and 'Calypso' mango varieties from three different producing regions in Australia harvested at five maturity stages (immature to ripe). By using mature and immature mangoes these authors were able to build SSC calibration models that had good precision to predict external mango population $\left(R_{\mathrm{V}}^{2}=0.92 ; \mathrm{SEP}=0.67 \%\right.$ SSC $)$.

Although SSC has been used as a quality parameter to evaluate mangoes, according to Subedi et al. (2007) the starch presented in the mesocarp is converted into soluble sugars during mango ripening and final eating quality is linked to SSC. However, the SWNIR spectroscopy is not recommended to assess SSC across ripening stage of mango fruit (Subedi and Walsh, 2011). Therefore, total carbohydrate content, as measured by DM, which encloses total starch and SSC of fruit at harvest and is linked to final mango eating quality. As such, DM PLS models were developed.

\subsection{2. $D M$}

The best prediction model was developed using raw spectra in a spectral window of $699-981 \mathrm{~nm}$. The optimal number of factors to obtain $82 \%$ of explained variance was achieved with $10 \mathrm{LV}$ and the best DM calibration model has a RMSE $\mathrm{CV}_{\text {of }} 8.81 \mathrm{~g} \mathrm{~kg}^{-1}, R_{\mathrm{CV}}^{2}$ of 0.84 , with a RPD of 2.51. The observed and predicted DM content by full cross validation can be observed in Fig. 5 .

In agreement with Subedi et al. (2007) who reported that DM models are more robust in ripening fruit (with conversion of starch to 


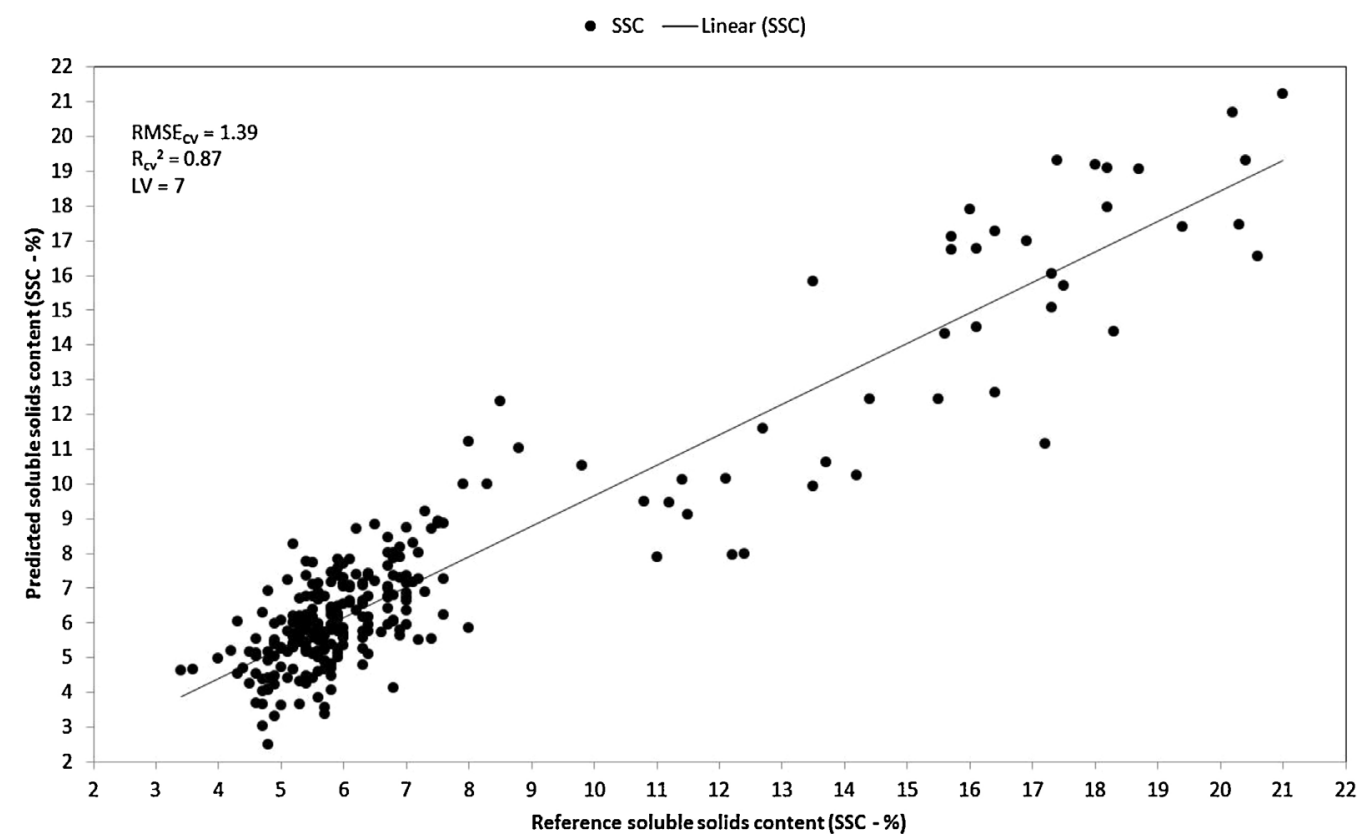

Fig. 4. Determined and predicted SSC (\%) of 'Palmer' mangoes harvested at different developmental stages (91-126 days after bloom) using a portable F-750 spectrometer.

sugar), the DM prediction models were better than the SSC, mainly the RPD value which indicates excellent precision accuracy (Nicolai et al., 2007). This trend might be due to absorption of $\mathrm{OH}$ groups at 960-990 nm from fruit constituents (water, carbohydrates as starch and sugars) (Bobelyn et al., 2010) since moisture content tends to gradually decline during fruit maturation (Rungpichayapichet et al., 2016) as starch and DM accumulates (Tandon and Kalra, 1983).

DM prediction has long being determined by NIR spectroscopy (Guthrie and Walsh, 1997; Saranwong et al., 2001, 2003, 2004; Walsh et al., 2004) with $R_{\mathrm{c}}^{2}>0.9$ and $\mathrm{RMSE}_{\mathrm{CV}}<1.19 \%$, but using bench top spectrometers.

With portable NIR spectrometer Greensill and Walsh (2000) using a prototype 'iQ'. Integrated Spectronics (Sydney, Australia) obtained the first DM prediction model with a $R_{\mathrm{V}}^{2}$ of 0.74 and a SEP of $1 \%$ MS on the window 300-1150 nm for 'Kensington Pride', 'R2E2', 'Celebration', and 'Calypso'. Walsh and Subedi (2016) using a Nirvana spectrometer in field reported a DM model performance of $R_{\mathrm{CV}} 0.94 \%$ and $\mathrm{RMS}_{\mathrm{CV}}$ $0.68 \%$. Lower RMSE $E_{p}$ values $(0.67$ and $0.51 \%$ ) were observed by Marques et al. (2016) using a MicroNIR 1700 in 'Tommy Atkins' mango.

Although results related to DM prediction can be found using portable NIR spectrometers, as physiological maturity is indexed by a plateau in the rate of DM accumulation, rather than a specific DM level per se, attempts to set a specific percentage of DM maturity standard should be season, region, and cultivar specific (Subedi et al., 2007). Therefore, the DM calibration model for 'Palmer' mango is fundamental to determine the correct maturity for exporting mangoes for distant markets.

However, the use of NIR spectroscopy to evaluate quality parameters in intact fruit faces problems related to heterogeneity caused by variability within-tree, within-orchard, fruit age and seasonal variability (Peirs et al., 2002). As such, to reduce the RMSE value of the

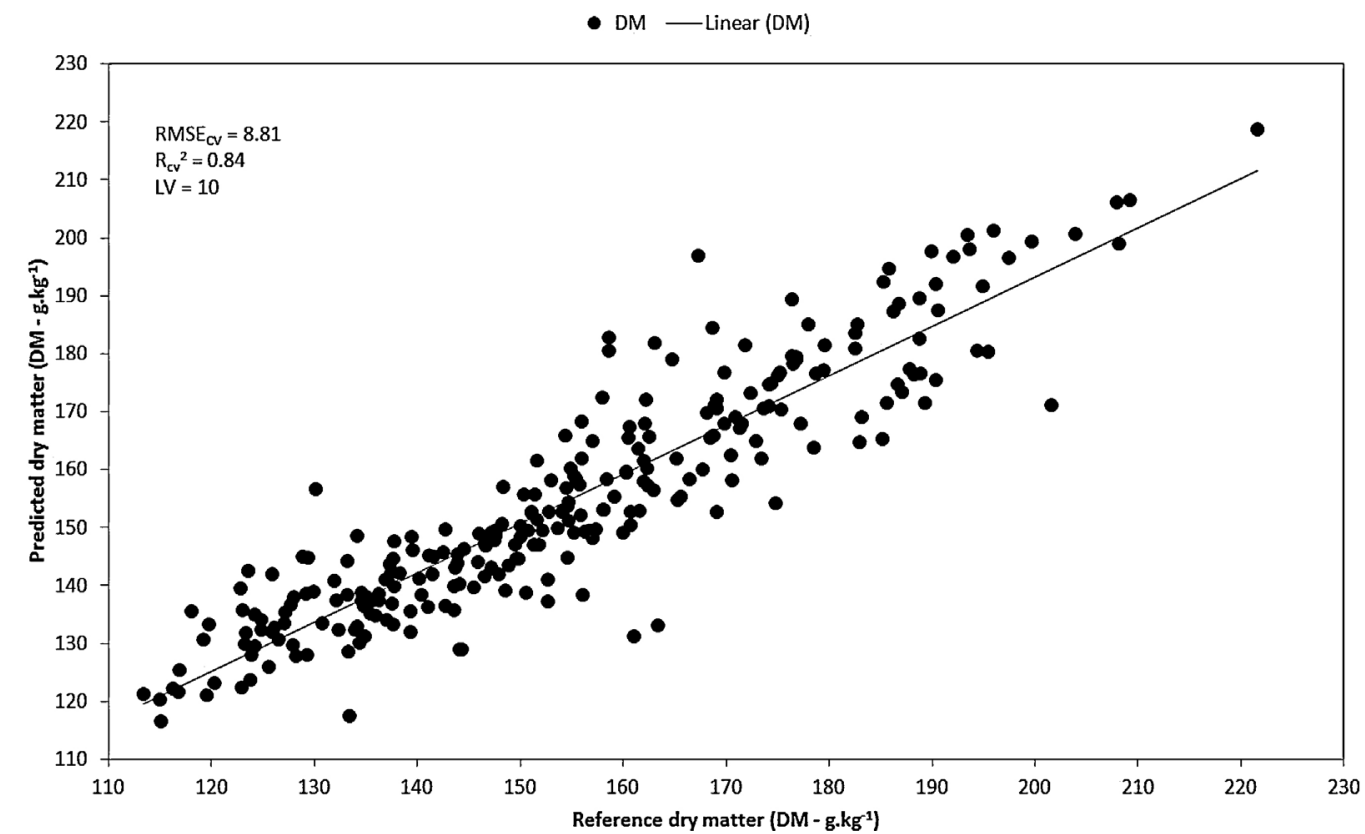

Fig. 5. Determined and predicted DM ( $\left.\mathrm{g} \mathrm{kg}^{-1}\right)$ of 'Palmer' mangoes harvested at different developmental stages (91-126 days after bloom) using a portable F-750 spectrometer. 
'Palmer' mango predictive models and to improve robustness, it is necessary to incorporate more sources of variation, to broad the range of the quality parameter values (Pasquini, 2003).

\section{Conclusions}

It was possible to develop calibration models for SSC and DM of 'Palmer' mango fruit using portable VIS-NIR spectrometer. Both PLS SSC and DM models can be used to predict 'Palmer' mango maturity. Poor calibration models were obtained for firmness. It is necessary to incorporate more sources of variation, to reduce RMSE values and improve robustness.

\section{Acknowledgments}

The authors would like to thank CAPES for providing the Doctorate fellowship to the first author, and Fundação de Amparo à Pesquisa do Estado de São Paulo (FAPESP) for funding this research (proc. 2015/ 03451-9) and providing the Doctorate fellowship (proc. 2015/256319). The authors also thank Tecnal equipamentos Científicos for lending the F-750 spectrometer.

\section{References}

A.O.A.C, 1997. Association of Official Analytical Chemists: Official.

Abbott, J.A., 1999. Quality measurement of fruits and vegetables. Postharvest Biol Technol. 15, 207-225.

AMIA, 2016. 2016 Mango Industry Quality Standards. http://www.industry.mangoes.net. au/resource-collection/2016/9/29/2016-mango-industry-quality-standards?rq= standard.

Assis, J.S., 2004. Cultivo da mangueira: colheita e pós-colheita.

Bally, I.S.E., 2011. Advances in research and development of mango industry. Rev. Bras. Frutic. 33, 57-63.

Betemps, D.L., Fachinello, J.C., Galarça, S.P., 2011. Espectroscopia do visível e infravermelho próximo (VIS/NIR) na avaliação da qualidade de mangas Tommy Atkins. Rev. Bras. Frutic. 33, 306-313.

Bleinroth, E.W., 1994. Manga para exportação: procedimentos de colheita e pós-colheita. In: Neto, Á.G., Gayet, J.P., Bleinroth, E.W., Matallo, M., Garcia, A.E., Ardito, E.F.C., Garcia, E.E.C., Bordin, M.R. (Eds.), EMBRAPA-SPI, Brasília, pp. 11-28 (chapter 2).

Bobelyn, E., Serban, A.S., Nicu, M., Lammertyn, J., Nicolai, B.M., Saeys, W., 2010. Postharvest quality of apple predicted by NIR-spectroscopy: study of the effect of biological variability on spectra and model performance. Postharvest Biol. Technol. $55,133-143$.

Chitarra, M.I.F., Chitarra, A.B., 2005. Pós-colheita de frutas e hortaliças: fisiologia e manuseio, 2nd ed. rev. e ampl. UFLA, Lavras 785 pp.

Delwiche, S.R., Mekwatanakarn, W., Wang, C.Y., 2008. Soluble solids and simple sugars measurement in intact mango using near infrared spectroscopy. HortTechnology 18, $410-416$.

Golic, M., Walsh, K.B., 2006. Robustness of calibration models based on near infrared spectroscopy for the in-line grading of stone fruit for total soluble solids content. Anal. Chim. Acta 555, 286-291.

Golic, M., Walsh, K.B., Lawson, P., 2003. Short-wavelength near-infrared spectra of sucrose, glucose, and fructose with respect to sugar concentration and temperature. Appl. Spectrosc. 57, 139-145.

Greensill, C.V., Walsh, K.B., 2000. A remote acceptance probe and illumination configuration for spectral assessment of internal attributes of intact fruit. Meas. Sci. Technol. 11, 1674-1684.

Guthrie, J.A., Walsh, K.B., 1997. Non-invasive assessment of pineapple and mango fruit quality using near infrared spectroscopy. Aust. J. Exp. Agric. 37, 253-263.

Halliday, D., Resnick, R., Walker, J., 2009. 8th ed. Fundamentos da Física, vol. 2 LTC. http://www.industry.mangoes.net.au/resource-collection/2016/3/6/dry-mattermatters.

Jha, S.N., Chopra, S., Kingsly, A.R.P., 2007. Modeling of colour values for nondestructive evaluation of maturity of mango. J. Food Eng. 78, 22-26.

Jha, S.N., Jaiswal, P., Narsaiah, K., Gupta, M., Bhardwaj, R., Singh, A.K., 2012. Nondestructive prediction of sweetness of intact mango using near infrared spectroscopy. Sci. Hortic. 138, 171-175.

Jha, S.N., Narsaiah, K., Jaiswal, P., Bhardwaj, R., Gupta, M., Kumar, R., Sharma, R., 2014. Nondestructive prediction of maturity of mango using near infrared spectroscopy. J. Food Eng. 124, 152-157.

Kader, A.A., Sommer, N.F., Arpaia, M.L., 2002. Postharvest handling systems: tropical fruits. In: Kader, A.A. (Ed.), Postharvest Technology of Horticultural Crops, 3rd ed. University of California, Agriculture and Natural Resources, Publication 3311, pp. $385-398$

Ketsa, S., Rattanamalee, S., Babprasert, C., 1991. Growth, development, biochemical changes and harvesting index of mango (Mangifera indica L.) cv. Tongdum. Kasetsart. J. Nat. Sci. 25, 391-399.

Krishnamurthy, S., Subramanyam, H., 1970. Respiratory climateric and chemical changes in the mango, Mangifera indica L. J. Am. Soc. Agron. 95, 333-337.

Lizada, C., 1993. Mango. In: Seymour, G.B., Taylor, J.E., Tucker, G.A. (Eds.), Biochemistry of Fruit Ripening. Chapman e Hall, Cambridge, pp. 255-271.

Mahayothee, B., Leitenberger, M., Neidhart, S., Mühlbauer, W., Carle, R., 2004. Nondestructive determination of maturity of Thai mangoes by near-infrared spectroscopy, Proceedings of the VII International Mango Symposium. Acta Hortic. $645,581-588$.

Makani, O.A., 2009. Mango Quality Survey and Sensory Evaluation of Mango (Mangifera indica L.) Cultivars. (Master Thesis) University of Queensland, Gatton, pp. 49.

Manica, I., 2001. Tecnologia, produção, agroindústria e exportação da manga. Cinco Continentes, Porto Alegre 618 pp.

Marques, E.J.N., Freitas, S.T., Pimentel, M.F., Pasquini, C., 2016. Rapid and nondestructive determination of quality parameters in the 'Tommy Atkins' mango using a novel handheld near infrared spectrometer. Food Chem. 197, 1207-1214.

Medlicott, A.P., Reynalds, S.B., New, S.W., Thompson, A.K., 1988. Harvest maturity effects on mango fruit ripening. Trop. Agric. 65, 153-157.

Mitra, S.K., Baldwin, E.A., 1997. Mango. In: Mitra, S. (Ed.), Postharvest Physiology and Storage of Tropical and Subtropical Fruits. CAB International, New York, NY, USA, pp. $85-122$.

Nicolai, B.M., Beullens, K., Bobelyn, E., Peirs, A., Saeys, W., Theron, K.I., Lammertyna, J., 2007. Nondestructive measurement of fruit and vegetable quality by means of NIR spectroscopy: a review. Postharvest Biol. Technol. 46, 99-118.

Pasquini, C., 2003. Near infrared spectroscopy: fundamentals, practical aspects and analytical applications. J. Braz. Chem. Soc. 14, 198-219.

Paull, R.E., Duarte, O., 2011. Introduction. In: Paull, R.E., Duarte, O. (Eds.), Tropical Fruits, 2nd ed. CAB International, London, UK, pp. 1-10.

Peirs, A., Tirry, J., Verlinden, B., Darius, P., Nicolaï, B.M., 2002. Effect of biological variability on the robustness of NIR-models for soluble solids content of apples. Postharvest Biol. Technol. 28, 269-280.

Popenoe, J., Hatton, T.T., Harding, P.L., 1958. Determination of maturity of hard green Haden and Zill mangos. Proc. Am. Soc. Hortic. Sci. 71, 326-329.

Popenoe, J., Long, W.G., 1957. Evaluation of starch content and specific gravity as measures of maturity of Florida mangos. Proc. Fla. State Hortic. Soc. 70, 272-274.

Ribeiro, S.M.R., 2006. Caracterização e avaliação do potencial antioxidante de mangas cultivadas no estado de Minas Gerais. (Tese (Doutorado em Bioquímica Agrí́cola)) Universidade Federal de Viçosa, Viçosa, pp. 149f.

Rungpichayapichet, P., Mahayothee, B., Nagle, M., Khuwijitjaru, P., Müller, J., 2016. Robust NIRS models for non-destructive prediction of postharvest fruit ripeness and quality in mango. Postharvest Biol. Technol. 111, 31-40.

Saranwong, S., Sornsrivichai, J., Kawano, S., 2004. Prediction of ripe-stage eating quality of mango fruit from its harvest quality measured nondestructively by near infrared spectroscopy. Postharvest Biol. Technol. 31, 137-145.

Saranwong, S., Sornsrivichai, J., Kawano, S., 2001. Improvement of PLS calibration for Brix value and dry matter of mango using information from MLR calibration. J. Near Infrared Spectrosc. 9, 287-295.

Saranwong, S., Sornsrivichai, J., Kawano, S., 2003. On-tree evaluation of harvesting quality of mango fruit using a hand-held NIR instrument. J. Near Infrared Spectrosc. 11, 283-293.

Schmilovitch, Z., Mizrach, A., Hoffman, A., Egozi, A., Fuchs, Y., 2000. Determination of mango physiological indices by near-infrared spectrometry. Postharvest Biol. Technol. 19, 245-252.

Soule, M.J., Harding, P.L., 1956. Changes in physical characters and chemical constituents of Haden mangos during ripening at 80 F. Proc. Fla. State Hortic. Soc. 69, 282-284.

Souza, F.V., 2007. Curva de crescimento e exportação de nutrientes e sódio por frutos de mangueira Palmer, Haden e Tommy Atkins. (Dissertação (Mestrado)) Universidade Estadual Paulista, Faculdade de Ciências Agrárias e Veterináriaspp. 54.

Story, A., Martin, A., 1996. AUF National Production Description Language. Australian United Fresh Fruit and Vegetables Association, Flemington, NSW.

Subedi, P.P., Walsh, K.B., Owens, G., 2007. Prediction of mango eating quality at harvest using short-wave near infrared spectrometry. Postharvest Biol. Technol. 43, 326-334.

Subedi, P.P., Walsh, K.B., 2011. Assessment of sugar and starch in intact banana and mango fruit by SWNIRS spectroscopy. Postharvest Biol. Technol. 62, 238-245.

Subedi, P.P., Walsh, K.B., 2009. Non-invasive techniques for measurement of fresh fruit firmness. Postharvest Biol. Technol. 51, 297-304.

TACO, 2011. Tabela Brasileira de Composição de Alimentos, 4th ed. revisada e ampliada. UNICAMP, Campinas, SP.

Tandon, D.K., Kalra, S.K., 1983. Changes in sugars, starch and amylases activity during development of mango fruit cv. Dashehari. J. Hortic. Sci. 58, 449-453.

Thanaraj, T., Terry, L.A., Bessant, C., 2009. Chemometric profiling of pre-climateric Sri Lankan mango fruit (Mangifera indica L.). Food Chem. 112, 786-794.

Valente, M., Leardi, R., Self, G., Luciano, G., Pain, J.P., 2009. Multivariate calibration of mango firmness using VIS/NIRS spectroscopy and acoustic impulse method. J. Food Eng. 94, 7-13.

Walsh, K.B., 2016. Dry matter matters. Mango Matters 23, 20-21.

Walsh, K.B., Golic, M., Greensill, C.V., 2004. Sorting of fruit using near infrared spectroscopy: application to a range of fruit and vegetables for soluble solids and dry matter content. J. Near Infrared Spectrosc. 12, 141-148.

Walsh, K.B., Subedi, P.P., 2016. In-field monitoring of mango fruit dry matter for maturity estimation, Proc. Int. Symposia on Abscission Processes in Horticulture and NonDestructive Assessment of Fruit Attributes. Acta Hortic. 1119, 273-278.

Xiaobo, Z., Jiewen, Z., Povey, M.J.W., Holmes, M., Hanpin, M., 2010. Variables selection methods in near-infrared spectroscopy. Anal. Chim. Acta 667, 14-32.

Yahia, E.M., 2011. Mango (Mangifera indica L.). In: In: Yahia, E.M. (Ed.), Postharvest Biology and Technology of Tropical and Subtropical Fruits, Cocona to Mango, vol. 3. Woodhead Publishing, pp. 492-565. 